\title{
VIOLÊNCIA DE GÊNERO E LEI MARIA DA PENHA: CONSIDERAÇÕES CRÍTICAS SOBRE A INSERÇÃO OBRIGATÓRIA DO AGRESSOR EM PROGRAMAS DE RECUPERAÇÃO OU ATENDIMENTO EM GRUPO COMO MEDIDA PROTETIVA DE URGÊNCIA
}

\author{
Bruna de Azevedo Castro ${ }^{1}$ \\ Samia Moda Cirino
}

\begin{abstract}
Resumo
$\mathrm{O}$ artigo analisa as novas medidas protetivas obrigatórias estipuladas na Lei 11.340/2006, de inserção do agressor em programas ou atendimento voltados à reeducação. A análise é realizada segundo a criminologia crítica feminista. Essa vertente permite questionar a legitimidade das medidas punitivistas em relação à violência contra a mulher, especialmente no que tange à seletividade do sistema penal. Verificou-se que as novas medidas preventivas implicam antecipação de punibilidade para aquele que sequer se enxerga como violador de direitos. Ainda, é apontada a necessidade de ressignificação das categorias de sexo e gênero para subverter a lógica opressora das relações de gênero.
\end{abstract}

PALAVRAS-CHAVE: Lei Maria da Penha. Medidas protetivas. Criminologia crítica feminista. Performatividade. Identidades sexuais.

\section{GENDER VIOLENCE AND MARIA DA PENHA LAW: CRITICAL CONSIDERATIONS ABOUT THE OBLIGATORY INSERTION OF THE AGGRESSOR IN GROUP RECOVERY OR SERVICE PROGRAMS AS A PROTECTIVE MEASURE OF EMERGENCY}

\begin{abstract}
The study analyzes the obligatory protective measures stipulated by Law 11.340 / 2006, for insertion of the aggressor in programs or assistance to re-education. The analysis occurs according to feminist critical criminology. This aspect allows to question the legitimacy of punitive measures in the issue of violence against women, especially with regard to the selectivity of the penal system. It was found that the new preventive measures involve anticipation of criminality to one that even sees itself as rights violator. Also pointed to the need for redefinition of sex and gender categories to subvert the opressive logic of gender relations.
\end{abstract}

KEYWORDS: Maria da Penha Law. Protective measures. Critical Feminist Criminology. Performativity. Sexual identities.

\footnotetext{
${ }^{1}$ Doutora em Direito pela Faculdade Autônoma de Direito (FADISP). Mestre em Direito pela Universidade Estadual de Maringá (UEM). Bacharel em Direito pela Universidade Estadual de Londrina (UEL). Professora do Curso de Graduação em Direito do Centro Universitário Integrado Brasil e do Curso de Graduação em Direito e Mestrado em Direito das Faculdades Londrina (FL). E-mail: brunaazcastro@gmail.com

${ }^{2}$ Doutora em Direito pela Universidade Federal do Paraná (UFPR). Mestre em Direito e Bacharel em Direito pela Universidade Estadual de Londrina (UEL). Professora no curso de Graduação em Direito e Mestrado em Direito das Faculdades Londrina (FL) e na Pós-Graduação em Direito do Instituto de Direito Constitucional e Cidadania (IDCC). Pesquisadora do Grupo de Pesquisa Liberdades em Disputa (UEL). E-mail: samiamoda@hotmail.com.
} 


\section{Introdução}

A promulgação da Lei Maria da Penha em 2006 (Lei n. 11.340) foi festejada por diferentes setores da sociedade brasileira por representar, para a época, grande avanço legislativo no enfrentamento da violência de gênero, praticada dentro e fora do âmbito doméstico e familiar.

A Lei Maria da Penha aumentou as margens penais previstas para a qualificadora ao crime de lesão corporal leve, quando praticado em situação de violência doméstica - contra ascendente, descendente, irmão, cônjuge ou companheiro, ou com quem conviva ou tenha convivido, ou, ainda, prevalecendo-se o agente das relações domésticas, de coabitação ou de hospitalidade. Antes de sua vigência, a pena prevista nessas hipóteses, que contemplam, mas não se limitam à violência contra a mulher, era de detenção de seis meses a um ano. Com a alteração em 2006, a pena passou a ser de detenção de três meses a três anos.

Nota-se, dessa maneira, que a incidência da Lei 11.340/2006 em matéria de direito material é mínima. O recrudescimento do sistema penal, compreendido como ampliação do âmbito de criminalização e endurecimento das sanções, ocorre posteriormente, destacando-se a criação de uma nova modalidade de homicídio qualificado (o feminicídio - artigo 121, $\S 2^{\circ}$, VI, Código Penal) em 2015 e a tipificação do descumprimento das medidas protetivas de urgência, decretadas para proteção da mulher em situação de violência (artigo 24-A, Lei 11.340/2006), que ocorreu em 2018.

A própria descrição da Lei Maria da Penha aponta sua principal característica e finalidade: criar mecanismos ou instrumentos para coibir a violência doméstica e familiar contra a mulher. Tais mecanismos situam-se majoritariamente no desenvolvimento de políticas públicas de prevenção e assistência à mulher em situação de violência e, quanto ao funcionamento do Poder Judiciário, caracterizam-se pela especificação da matéria, com a criação dos Juizados de Violência Doméstica e Familiar contra a Mulher (artigo 14, Lei 11.340/2006), previsão de inaplicabilidade de quaisquer instrumentos despenalizadores da Lei 9.099/1995, tais como a suspensão condicional do processo e transação penal (vide artigo 41, 
Lei 11.340/2006) e detalhada regulamentação das medidas protetivas de urgência (artigo 18 e seguintes).

O objetivo deste artigo é analisar criticamente a recente alteração legislativa quanto às medidas protetivas de urgência, previstas no artigo 22 da Lei Maria da Penha, que insere os incisos VI e VII ao referido dispositivo, possibilitando ao juiz que determine imediatamente, desde que constatada a situação de violência doméstica e familiar contra a mulher, a inclusão obrigatória do agressor em programas de recuperação e reeducação (inciso VI) ou sua submissão a atendimento psicossocial individual ou em grupo (inciso VII).

Passados catorze anos desde sua promulgação, verifica-se que a Lei Maria da Penha sofreu diversas modificações legislativas voltadas ao recrudescimento do sistema penal com o fim de coibir ou reduzir a violência de gênero. Contudo, o que se tem na realidade é uma prática destoante dos fins apregoados pela legislação vigente, que é voltada em tese à prevenção da violência. Os instrumentos de prevenção criados e aperfeiçoados pela Lei Maria da Penha, tais como medidas protetivas de urgência, mostram-se pouco eficientes e, por isso, não raras vezes convertem-se em mecanismos punitivos.

Dentro da perspectiva de uma Criminologia crítica feminista, concorrem movimentos contrapostos que transitam entre a deslegitimação do sistema penal, com fundamento na crítica do controle social e punitivo em relação às mulheres na sociedade capitalista, e sua relegitimação política não só "ao demandar sua intervenção para criminalização da violência contra a mulher" (ANDRADE, 2020, p. 23), mas também quando se faz uso meramente simbólico das medidas de prevenção.

Para além da perspectiva simbólica, é necessário indagar se tais medidas preventivas não estão se convertendo em punição antecipada, o que relegitima o sistema penal punitivo e sua estrutura seletiva, fundamentada em discriminação de raça/etnia e classe.

Ainda, de acordo com a crítica feminista realizada por Judith Butler, é realizada a análise da constituição das identidades sexuais a fim de demonstrar que a gênese da violência contra a mulher reside na própria construção do sexo e do gênero. O objeto, portanto, é demonstrar a necessidade de subverter a lógica opressora das relações de poder que instituem os papeis sociais de gênero.

\section{Criminologia crítica feminista e punitivismo}


A criminologia enquanto disciplina científica desenvolveu-se em um espaço acadêmico essencialmente masculinizado que, embora muitas vezes se faça a crítica do sistema penal quanto às discriminações de raça e classe, não ocorre problematização quanto ao papel de subordinação relegado à mulher no meio social, científico e dentro do próprio sistema de justiça criminal (ANDRADE, 2016, p. 15).

A crise de legitimidade do sistema penal, apontada pelo extenso horizonte da criminologia crítica, fundamenta-se em suas "promessas não cumpridas": a proteção de bens jurídicos (pessoa, patrimônio, liberdade, dignidade sexual etc.); a promessa de combate à criminalidade, através da retribuição, prevenção geral e prevenção especial positiva (ressocialização dos condenados; a promessa de uma aplicação igualitária das penas) (ANDRADE, 1999, p. 106).

A partir do século XVIII, inicia-se a fase do sistema penal adequado ao capitalismo da Revolução industrial: passa a ser um sistema de "gerenciamento das ilegalidades", transferindo a vingança do soberano para a defesa da sociedade, para a qual a prisão é palco da aplicação de disciplinas de controle sobre os corpos humanos considerados "disfuncionais" e devem ser, por isso mesmo, objeto de medição, vigilância e correção (BATISTA 2011, p. 95).

Atualmente, essa fase do sistema penal não se encontra superada e é possível identificar o acréscimo de algumas capeadas funções na execução da pena privativa de liberdade, que não podem constar do discurso oficial de legitimação, porque violam escandalosamente a ordem constitucional e comumente se apresentam como efeitos decorrentes da própria prisionização.

Exemplo disso é a perda da individualidade, a transformação do indivíduo em um número, um corpo a ser controlado vinte e quatro horas por dia (SÁ, 2007, p. 115); e é por meio desse sistema, absolutamente distinto da realidade da vida social, que se pretende "transformar" o indivíduo que delinquiu em alguém preparado ou "digno" para novamente conviver em sociedade.

Precisamente nesse aspecto é que se inserem as necessárias críticas vertidas ao tratamento da violência de gênero, fruto de um discurso punitivista de (re)legitimação do sistema penal e defesa da pena de prisão, que necessariamente devem ser enfrentadas pela criminologia crítica feminista. 
$\mathrm{Na}$ legislação brasileira, nota-se a intervenção de dois movimentos que propulsionam forças contrárias: o Direito Penal mínimo e o direito penal máximo. O primeiro, partindo do princípio da ofensividade e intervenção mínima do Direito Penal, volta-se à despenalização, no sentido de evitar o encarceramento por meio de medidas alternativas em sentido amplo (suspensão condicional do processo, transação penal, substituição das penas privativas de liberdade etc.).

De outro lado, o segundo movimento, de máxima intervenção penal, verifica-se na intensa produção legislativa penal para novas criminalizações, aumento de penas, flexibilização de garantias individuais, ampliação do uso da prisão preventiva. No contexto dessa ambiguidade é que deve ser situado coerentemente a criminologia feminista para a crítica do sistema penal (ANDRADE, 1999, p. 108).

Sendo insuficiente a inserção da perspectiva feminina nos discursos hegemônicos masculinizados, alheios a qualquer recorte de gênero, a criminologia feminista tem o próprio recorte epistemológico e cria suas categorias partindo de um discurso que denuncia e torna visível as relações de opressão na violência de gênero (ANDRADE, 2016, p. 18).

Dentre as diversas perspectivas teóricas que definem violência de gênero, destaca-se a concepção segundo a qual violência de gênero como uma relação de poder dinâmica e relacional, que vai além da noção de dominação patriarcal (SANTOS; PASINATO, 2005; p. 14) e não exclui da análise a opressão exercida contra outras categorias sociais, dentro da violência de gênero.

A criminologia crítica feminista é uma perspectiva teórica que, partindo da construção de novas categorias e do próprio recorte epistemológico, promove a crítica do sistema penal quando ao tratamento da violência de gênero e do encarceramento feminino, sem negligenciar aspectos relacionados à seletividade do sistema punitivo baseada na discriminação de raça e classe social. Isso porque a criminologia feminista não deve ser um "mecanismo de defesa de uma violência historicamente detectada" no sistema punitivo (ANDRADE, 1999, p. 111).

Nesse sentido, entende-se que a criminologia crítica feminista:

[..] sem se conformar com os altos índices de violência contra as mulheres, deve reconhecer a ineficácia da pena para o combate das violências de gênero, compreendendo que toda a estrutura da lei é fundamentada na dominação patriarcal. A adesão ao pleito abolicionista, então, não significa relegar a violência 
generificada ao âmbito privado, mas enfrentá-la sem recorrer à repressão penal (ANDRADE, 2016, p. 24).

O "punitivismo", compreendido como um movimento teórico que se reflete na política-criminal, ou uma visão de mundo que coloca em destaque absoluto a necessidade de mais punições e sanções mais severas como respostas à criminalidade, é também um movimento de defesa do encarceramento. Ou seja, de uma maneira geral, o punitivismo faz uso da prisão como elemento discursivo para apresentar soluções presumidamente eficazes diante do problema do constante aumento ou da não redução da criminalidade (especialmente a patrimonial).

Com isso, reforça-se a normalidade da privação de liberdade no ideário popular, como instrumento necessário sem o qual a sociedade não subsiste. Aliás, "nossa sensação de familiaridade com a prisão deriva em parte das representações das prisões em filmes e outras mídias visuais" (DAVIS, 2018, p. 18).

Se a criminologia feminista adere a um discurso parcialmente punitivista, de relegitimação do sistema penal para combater especificamente a violência de gênero, ignorase as contradições internas do sistema prisional, inclusive no que tange ao encarceramento feminino. Não coexistirão dois sistemas punitivos distintos.

A utilização da prisão como principal forma de responder ao fenômeno criminal não tem o condão de remover as desigualdades de gênero e combater essa específica forma de violência, simplesmente porque a prisão não se presta a eliminar ilegalidades ou desigualdades, mas, ao contrário, é instrumento de violência e ainda pode criar outras desigualdades.

Não se pode ignorar, portanto, que o sistema punitivo caracterizado pelo uso excessivo da prisão também afeta o gênero e, quanto à criminalidade feminina, é utilizado para incentivar e reiterar os papeis tradicionais e "adequados" da mulher, de modo que a prisioneira também é controlada, vigiada e "treinada", dentro das instituições totais, para exercer as funções de culinária, limpeza, costura (DAVIS, 2018, p. 77).

Pode o sistema criminal sofrer ressignificações ao longo da história, mas não abandona a "missão" de desconstrução da individualidade pelo controle ou pela morte dos "indesejados", "que tem na hierarquia racial um dos pilares de sustentação" (BORGES, 2019, p. 44). 


\section{Novas medidas protetivas na Lei 11.340/2006 e antecipação de punibilidade}

A Lei 11.340/2006 - Lei Maria da Penha - representou, indubitavelmente, uma importante conquista dos movimentos feministas para a construção de uma política pública de enfrentamento e prevenção à violência de gênero, particularmente a violência doméstica contra a mulher.

No Capítulo II da lei referida, a partir de seu artigo 18, estão previstas as medidas protetivas de urgência, classificadas em: a) medidas protetivas que obrigam o agressor; b) medidas protetivas da vítima.

As medidas protetivas que obrigam o agressor também se destinam à tutela da vítima, ainda que indiretamente, e estão elencadas em um rol não taxativo do artigo 22 da Lei Maria da Penha:

Art. 22. Constatada a prática de violência doméstica e familiar contra a mulher, nos termos desta Lei, o juiz poderá aplicar, de imediato, ao agressor, em conjunto ou separadamente, as seguintes medidas protetivas de urgência, entre outras:

I - suspensão da posse ou restrição do porte de armas, com comunicação ao órgão competente, nos termos da Lei $\mathrm{n}^{\circ} 10.826$, de 22 de dezembro de 2003;

II - afastamento do lar, domicílio ou local de convivência com a ofendida;

III - proibição de determinadas condutas, entre as quais:

a) aproximação da ofendida, de seus familiares e das testemunhas, fixando o limite mínimo de distância entre estes e o agressor;

b) contato com a ofendida, seus familiares e testemunhas por qualquer meio de comunicação;

c) frequentação de determinados lugares a fim de preservar a integridade física e psicológica da ofendida;

IV - restrição ou suspensão de visitas aos dependentes menores, ouvida a equipe de atendimento multidisciplinar ou serviço similar;

$\mathrm{V}$ - prestação de alimentos provisionais ou provisórios.

VI - comparecimento do agressor a programas de recuperação e reeducação; e

VII - acompanhamento psicossocial do agressor, por meio de atendimento individual e/ou em grupo de apoio.

As medidas protetivas que obrigam o agressor possuem natureza cautelar e devem ser determinadas pelo juiz, com prévia manifestação de vontade da vítima (DIAS, 2007, p. 78), salvo nos casos de risco atual ou iminente à vida ou integridade física, hipótese em que a própria autoridade policial pode determinar o afastamento do agressor (art. 12-C, Lei 11.340/2006). 
Por estarem inseridos entre as medidas que se destinam a proteção da vítima, os instrumentos previstos no artigo 22, que obrigam o agressor a fazer ou deixar de fazer algo, devem revestir-se de tal natureza.

As medidas previstas nos incisos VI e VII, objeto da presente análise, foram inseridas pela Lei n. 13.984/2020. O projeto que deu origem a essa lei é de autoria da Comissão de Direitos Humanos e Legislação Participativa do Senado Federal (PLS n. 9/2016), no qual se destaca a seguinte justificativa:

A Comissão de Direitos Humanos e Legislação Participativa realizou no dia $1^{\circ}$ de dezembro de 2015 audiência pública para debater sobre iniciativas de reeducação de homens autores de violência doméstica e familiar contra a mulher.

$\mathrm{Na}$ ocasião, os convidados relataram experiências bem-sucedidas relacionadas à participação dos autores de violência em cursos e encontros em que refletem sobre temas como identidade de gênero, machismo, assunção de responsabilidade por seus próprios atos, entre outros.

Alguns estados já contam com programas em pleno funcionamento. É o caso, por exemplo, de São Paulo, com o projeto Tempo de Despertar, inspirado nas iniciativas pioneiras do Rio Grande do Norte, com o Grupo Reflexivo de Homens: Por uma Atitude de Paz, e do Mato Grosso, com o projeto Lá em Casa quem Manda é o Respeito.

Algumas das maiores conquistas dessas ações são os baixos índices de reincidência dos agressores, aliados ao seu potencial para provocar mudanças significativas nas vidas desses homens, sobretudo na ressignificação de seus papeis.

Com inspiração nessas exitosas experiências, apresentamos o presente projeto, que institui a medida protetiva de frequência a centros de educação e de reabilitação, pois não vemos razão para não fomentar, em nível nacional, a prática adotada, com sucesso, por várias unidades da federação.

Segundo a justificativa do Projeto, verifica-se que a frequência do agressor em programas de "reeducação" apresentou resultados positivos em projetos desenvolvidos nos estados de São Paulo, Rio Grande do Norte e Mato Grosso, consistentes nos "baixos índices de reincidência", do qual se extrai conclusão positiva acerca desse tipo de medida para "mudanças significativas nas vidas desses homens, sobretudo na ressignificação de seus papeis". Ao final, note-se a seguinte afirmação: "pois não vemos razão para não fomentar, em nível nacional, a prática adotada, com sucesso, por várias unidades da federação”. Os trechos destacados apresentam pontos problemáticos quanto ao tratamento da violência de gênero, o seu significado para o agressor e o caráter ressocializador dessas medidas, aliadas à prática de uma punição antecipada. 
Em primeiro lugar, é falsa a inferência de que os baixos índices de reincidência refletem o sucesso dos programas de "reeducação" do agressor porque promoveram mudanças significativas em suas vidas, com ressignificação de seus papeis.

A não-reincidência representa, na verdade, um freio na escala evolutiva da violência de gênero quando, para determinados agressores, que não voltam a cometer a violência física, o retorno às escalas inferiores de violência psicológica representa um progresso do ponto de vista jurídico-penal, já que tais condutas não integram a estatística oficial de violência contra a mulher.

A ressignificação dos papeis do agressor e "mudanças importantes em sua vida", sem que isso decorra de uma verdadeira desconstrução dos papeis de gênero, implicam somente uma transferência de um papel para o outro, mas que igualmente compõem a lógica de uma relação de opressão, fundamentada no papel subalterno e vulnerável da mulher: o agressor passa a ser o protetor.

Dessa forma, a inserção obrigatória do agressor em programas de reeducação desde o início da investigação, ou seja, quando ele e a vítima ainda estão assimilando o primeiro passo para a tentativa de destruição uma relação abusiva, representa antecipação de punibilidade na qual o seu papel de agressor, até então não assimilado por ele, não só é exposto, mas também reconfigurado.

Em outras palavras: se o agressor ainda não se entende como tal e não interpreta sua conduta como violação de um direito e sim como exercício de outro direito, de acordo com os papeis de gênero, a pretensa ressignificação (para "reeducação"), na realidade, implicará, se bem-sucedida, na transformação do agressor em protetor, mas a gênese da violência de gênero mantém-se intacta.

Como se verá adiante, não há possibilidade de promover a "reeducação" do agressor sem a desconstrução do próprio gênero, uma vez que a origem da violência de gênero não reside da agressão em si, mas na posição de inferioridade e vulnerabilidade tradicionalmente atribuída à mulher.

\section{A gênese da violência de gênero}

Como visto nas seções anteriores, não se nega a importância da Lei Maria da Penha como marco regulatório necessário para o enfrentamento da violência de gênero contra a 
mulher. Contudo, a efetividade dessa norma não será viabilizada pela tendência de recrudescimento do sistema punitivista nesse tema, em um uso simbólico do direito penal, eis que a adoção dessa estratégia acaba por reforçar a estrutura seletiva do sistema penal, fundamentada em discriminação de raça/etnia e classe.

Se o escopo da norma é o de viabilizar meios para a prevenção da violência contra a mulher, esses mecanismos devem ser capazes de modificar a gênese desse problema. A questão principal que se levante é se medidas mais punitivistas serão capazes de inverter a lógica que atribui às mulheres um papel subalterno e vulnerável na sociedade e aos homens o papel de dominação, exploração e opressão das mulheres. Ou ainda, se as medidas de inclusão obrigatória do agressor em programas de recuperação e reeducação, ou sua submissão a atendimento psicossocial individual ou em grupo, serão estruturadas de modo a subverter esses papeis de gênero na sociedade.

Diante dessas questões, cabe à crítica feminista "compreender como a categoria das mulheres, o sujeito do feminismo, é produzida e reprimida pelas mesmas estruturas de poder por intermédio das quais se busca a emancipação" (BUTLER, 2015, p. 20). Ou seja, é tarefa essencial expor a lógica da construção dos corpos sexuados e das identidades sexuais dos sujeitos pelas relações de poder em determinados contextos sócio-históricos. Portanto, cabe à crítica feminista desvelar o modo como ocorre a constituição do gênero e do sexo na nossa sociedade, estabelecidos impositivamente a partir de uma interpretação cultural da diferença sexual e da lógica das relações de poder.

A crítica que subjaz a esse intento abala as pautas identitárias, que por muito tempo orientaram as teorias feministas. Essas políticas identitárias acabam por reduzir o sujeito a apenas um aspecto das identidades sociais, como a ideia propagada de uma essência feminina. Para essa corrente, ser mulher e, portanto, estar abrangida nos movimentos feministas, depende da identificação de uma feminilidade.

Argumento falacioso que acaba por confirmar a lógica binária excludente e o papel frágil, subalterno da mulher na sociedade. Biologicamente e culturalmente determinadas como frágeis, o papel social primordial das mulheres estaria circunscrito ao âmbito familiar, de reprodução e cuidados domésticos, em uma dominação masculina do seu corpo e subjetividade.

Acreditar em uma identidade essencial, definida e estável, é abandonar qualquer possibilidade de emancipação da mulher; é fazer com que o sujeito sujeitado reproduza a 
própria sujeição, ao acreditar e atuar o papel subalterno que lhe foi imposto segundo uma lógica sexista.

O que se questionada em tal estrutura é que o gênero, ser mulher, ou ser homem, não pode ser a síntese de um sujeito, portanto não por ser a base para determinar a história de uma pessoa. Ora, "se alguém é uma mulher, isso certamente não tudo o que esse alguém é" (BUTLER, 2015, p. 21).

O termo não é exaustivo, pois, muito além de aspectos biologizantes, há interseções políticas, culturais, raciais e de classe, em contextos específicos, que atuam sobre o sujeito nesse processo de constituição de si. Portanto, Judith Butler (2015, p. 244) adverte que o gênero não deve ser entendido como uma identidade estável, mas como uma identidade tenuamente constituída no tempo, como uma temporalidade social constituída.

Disso decorre que o gênero, na nossa sociedade, é uma identidade constituída, ou, conforme teoria butleriana, uma realização performativa. Isso quer dizer que o gênero é constituído mediante performances sociais contínuas, na forma de normas que incidem reiteradamente sobre o sujeito ao longo de sua vida. Em outras palavras, o sujeito está inserido em uma matriz de normas que são reiteradas repetidas, de modo mascarado, no processo de constituição do corpo e da subjetividade com intuito de inviabilizar a proliferação das "configurações de gênero fora das estruturas restritivas da dominação masculinista e da heterossexualidade compulsória" (BUTLER, 2015, p. 244).

O caráter performativo do gênero significa que as identidades decorrentes são constituídas em um processo reiterado e contínuo segundo regras que condicionam e restringem as práticas culturalmente inteligíveis da identidade. Essas regras, que operam por repetição, são "parcialmente estruturadas em conformidade com matrizes da hierarquia do gênero e da heterossexualidade compulsória" (BUTLER, 2015, p. 250).

Diante disso, ao afirmar que o sujeito é constituído, Judith Butler (2015, p. 250), em uma perspectiva foucaultiana, refere-se ao fato de que "o sujeito é uma consequência de certos discursos regidos por regras, os quais governam a invocação inteligível da identidade".

Não há como compreender o sujeito fora do contexto que está inserido e sem considerar as relações de poder que incidem para conformá-lo e constituí-lo. É dentro de um de um extenso tecido social que criamos quem somos, desfazendo-nos e refazendo-nos continuamente. 
Essa trama faz parte do que Judith Butler (2009, p. 123) denomina de paradoxo da autonomia, eis que no processo de constituição de si a capacidade de ação do sujeito pode ser restringida ou expandida de acordo com as regulações do gênero, do que é inteligível em termos de expressão do gênero.

Essa constituição performativa das identidades sexuais é explicada pela autora (BUTLER, 2002, p. 326) no seguinte exemplo de construção do feminino na nossa sociedade:

À medida que a denominação de menina seja transitiva, quer dizer, inicie o processo mediante o qual se obrigada alguém a adotar a posição de menina, o termo, ou mais precisamente, seu poder simbólico, governa a formação de uma feminidade interpretada corporalmente, que nunca se assemelha por completo à norma. Essa é uma menina que está obrigada a citar a norma para que a considerem um sujeito viável e para poder conservar essa posição. De modo que a feminilidade não é produto de uma decisão, mas de uma citação obrigatória de uma norma, uma citação cuja completa historicidade não pode ser dissociada das relações de disciplina, regulação e castigo. Na verdade, não existe alguém que acate uma norma de gênero. Ao contrário, essa citação da norma de gênero é necessária para que alguém se considere como alguém, para chegar a ser alguém viável, já que essa formação do sujeito depende da operação prévia das normas legitimadoras de gênero.

Isso não quer dizer que o sujeito é determinado pelas regras segundo as quais é moldado, porque não se trata de um ato fundador do sujeito, "mas de um processo regulado de repetição que tanto se oculta quanto impõe suas regras, precisamente por meio da produção de efeitos substancializantes" (BUTLER, 2015, p. 250). Isto é, diz-se que o sujeito é determinável, mas não determinado, eis que nesse processo o sujeito não só assimila, mas também ressignifica essas normas que repetidamente incidem sobre ele nos processos de identificação.

Essas normas que incidem sobre o sujeito, como a heterossexualização, seguem a lógica das relações de poder estabelecidas em determinados contextos sociais e históricos. Nas relações de gênero, de acordo com a teoria butleriana, esses regimes sexuais reguladores são representados pela lógica binária falocêntrica e heteronormativa. Segundo essa linha de pensamento, trata-se de uma ordem reguladora falocêntrica porque o homem é sujeito na sociedade, detentor do simbólico do falo. Já a mulher, é o outro, justamente porque lhe falta este elemento corporal significante. 
Além disso, essa lógica é heteronormativa porque impõe as identificações de acordo com a relação mimética entre sexo e gênero, ou seja, do aspecto meramente biológico do sexo e do determinismo cultural do gênero a partir da interpretação desse corpo sexuado. Portanto, a heteronormatividade parte da premissa segundo a qual o gênero reflete o sexo ou é por ele restrito.

Quando esse aspecto fictício, ou performativo, é desvelado, "tem-se a impressão de que o gênero não é tão determinado e tão fixo quanto na formulação de que a biologia é destino. Nesse caso, não a biologia, mas cultura se torna o destino" (BUTLER, 2015, p. 29).

Dentro dessa matriz heteronormativa as identidades sexuais são constituídas a partir do sexo atribuído no nascimento, em uma espécie de materialização dessa norma, marcando o que o sujeito deverá ser em sua trajetória.

Diante disso, Judith Butler (2009, p. 119) desvela que o sexo é o aspecto mais concreto da constituição dos sujeitos pelas relações de poder, eis que, nos termos da lógica heteronormativa, é utilizado como um vetor para materializar a diferença sexual e restringir suas ações dentro de quadros previamente estabelecidos de reconhecimento e inteligibilidade:

[...] essa noção de "sexo atribuído" - sexo "atribuído" no nascimento - pressupõe que o sexo é produzido e reiterado socialmente e que ele vem a nós não a partir meramente de uma reflexão psicológica que cada uma de nós faz sobre si mesma, mas a partir de uma interrogação crítica que cada uma de nós faz de uma categoria social que é atribuída a nós que nos excede em sua generalidade e poder, mas que também, consequentemente, se mostra no nosso corpo.

Disso resulta que o sexo, na nossa sociedade, não é uma determinação biológica, mas é produzido e estabelecido como pré-discursivo, como uma superfície politicamente neutra sobre a qual age a cultura (BUTLER, 2015, p. 27). Por sua vez, o gênero é a estilização repetida do corpo, um conjunto de atos repetidos no interior de uma estrutura reguladora altamente rígida, a qual se cristaliza no tempo para produzir a aparência de uma substância, de uma classe natural de ser (BUTLER, 2015, p. 69).

Para superar esse sistema opressivo, Judith Butler (2015, p. 26) propõe a "descontinuidade radical entre corpos sexuados e gêneros culturalmente construídos". Conforme ressalta a autora (BUTLER, 2015, p. 76), "localizar o mecanismo mediante o qual o sexo se transforma em gênero é pretender estabelecer, em termos não biológicos, não só o 
caráter de construção do gênero, seu status não natural e não necessário, mas também a universalidade cultural da opressão".

A causa de opressão da mulher na teoria butleriana é decorrência da estratégia que explica o sujeito mediante o desenvolvimento lógico da biologia. Segundo esse fundamento, "defende-se que as mulheres devem cumprir certas funções sociais e não outras, ou, na verdade, que as mulheres deveriam limitar-se absolutamente ao terreno reprodutivo" (BUTLER, 2002, p. 61).

Enquanto não foram alterados radicalmente os termos da constituição performativa das identidades sexuais, a suposta autonomia estará enredada em sujeição, pois a escolha individual mostrará ser dependente, desde o início, de condições que nenhum de nós produziu ou desejou (BUTLER, 2009, p. 123). Em outras palavras, o mundo social, sinal de nossa heteronomia constitutiva, precisa mudar para que a autonomia se torne possível.

De acordo com essa linha de pensamento, é preciso subverter essa lógica opressora que limita o papel dos sujeitos de acordo com aspectos meramente biológicos e do significado cultural que lhes são atribuídos, abrindo-se, então, um novo horizonte para as identidades sexuais, até então, ininteligível.

\section{Considerações finais}

Diante do estudo realizado no presente artigo, pode-se concluir que a Lei 11.340/2006, conquanto represente significativa conquista dos movimentos feministas para denunciar e visibilizar a violência de gênero, tem sido utilizada como vitrine de medidas inócuas, que não são implementadas ao lado de uma política pública efetivamente voltada à prevenção da violência.

Além disso, a violência de gênero também é utilizada como instrumento para legitimação do sistema penal dentro de uma lógica punitivista (novas incriminações, aumento de penas, flexibilização de garantias, antecipação de punibilidade). Essa manipulação discursiva deve ser objeto de uma crítica detida da criminologia crítica feminista que, com recorte epistemológico próprio, não deve desconsiderar o fator de seletividade do sistema punitivo fundamentada na discriminação de raça e classe social. Por isso, é possível afirmar que não pode existir criminologia feminista que não seja crítica do sistema penal, suas contradições e seletividade. 
As novas medidas de proteção da Lei Maria da Penha, inseridas pela Lei 13.984/2020, que permitem a inserção cautelar obrigatória do agressor, ainda durante a investigação preliminar, em programas de reeducação ou assistência social voltada à sua reeducação, eficazes ou não na contenção dos índices de reincidência, promovem unicamente a transmutação de um papel em outro, mas ambos decorrentes do papel de gênero atribuído à mulher: de inferioridade e vulnerabilidade.

Não é possível implementar a reeducação do agressor, como pretende a referida lei, sem inverter a lógica opressora que limita o papel dos sujeitos de acordo com aspectos meramente biológicos e do significado cultural que lhes são atribuídos. Se o sujeito continuar a ser constituído de acordo com a lógica falocêntrica e heteronormativa, que coloca a mulher como o outro nas relações sociais e que constrói as identidades sexuais de acordo com aspectos biologizantes, inviável que o agressor compreenda que a mulher é seu par e, portanto, ele não detém o domínio sobre seu corpo e sua subjetividade.

A subversão dessa lógica opressora, nos termos da teoria butleriana, requer a ressignificação do sexo e do gênero desvinculados de aspectos naturais. Não se quer afirmar com isso que os dados biológicos não constituam as identidades sexuais. O que se afirma é que não são os únicos dados a compor o sujeito. Aspectos relacionados à política, economia, cultura, classe, raça, também incidem sobre o sujeito para constituí-lo.

Em especial no direito penal ganham relevância os aspectos imbricados de raça e classe, eis que a violência contra a mulher não pode ser combatida em termos de punitivismo seletista. Em outras palavras, punir o agressor antecipadamente por meio dessas medidas de urgência inseridas na Lei Maria da Penha não terá o efeito esperado de alterar sua compreensão sobre as relações de gênero.

Consoante afirma a criminologia feminista crítica, a violência contra a mulher deve ser combatida por mecanismos, políticas públicas, que incidam sobre a gênese da vulnerabilidade da mulher na nossa sociedade. E essa gênese reside na própria constituição do sujeito pelas relações de poder em determinados contextos sócio-históricos, que consideram aspectos de classe, raça e gênero para delimitar quem será um sujeito humanamente inteligível, bem como as possibilidades de uma vida vivível.

\section{Bibliografia}


ANDRADE, C. D. Por uma criminologia crítica feminista. Revista Espaço Acadêmico (UEM), v. 16, p. 14-25, 2016.

ANDRADE, Vera Regina Pereira de. Criminologia e feminismo: da mulher como vítima à mulher como sujeito de construção da cidadania. In: CAMPOS, Carmen Hein de. Criminologia e feminismo. Porto Alegre: Sulina, 1999.

Criminologia em pedaços: manifesto por uma aliança para a brasilidade. Boletim IBCCRIM, São Paulo, v. 28, n. 328, p. 23-26., mar. 2020.

BATISTA, Vera Malaguti. Introdução crítica à criminologia brasileira. Rio de Janeiro: Revan, 2011.

BORGES, Juliana. Encarceramento em masssa. São Paulo: Sueli Carneiro; Pólen, 2019.

BUTLER, Judith. Cuerpos que importan: sobre los limites materiales y discursivos del "sexo". $1^{\mathrm{a}}$ ed. Buenos Aires: Paidós, 2002.

Desdiagnosticando o gênero. In Physis Revista de Saúde Coletiva. Rio de Janeiro. 19[1], 2009, p. 95-126.

Problemas de gênero: feminismo e subversão da identidade. $8^{a}$ ed. Rio de Janeiro: Civilização Brasileira, 2015.

Quadros de guerra: quando a vida é passível de luto? $1^{\text {a }}$ ed. Rio de Janeiro: Civilização Brasileira, 2015.

Relatar a si mesmo: crítica da violência ética. 1.ed. Belo Horizonte: Autêntica Editora, 2015.

. Vida precária: os poderes do luto e da violência. $1^{a}$ ed. Belo Horizonte: Autêntica Editora, 2019.

DAVIS, Ângela. Estarão as prisões obsoletas? Trad. Marina Vargas. Rio de Janeiro: Difel, 2018.

DIAS, Maria Berenice. A Lei Maria da Penha na justiça: a efetividade da Lei 11.340/2006 de combate à violência doméstica e familiar contra a mulher. São Paulo: RT, 2007.

GERMANO, Idilva Maria Pires; MONTEIRO, Rebeca Áurea Ferreira Gomes; LIBERATO, Mariana Tavares Cavalcanti. Criminologia Crítica, Feminismo e Interseccionalidade na Abordagem do Aumento do Encarceramento Feminino. Psicologia: ciência e profissão, Brasília , v. 38, n. spe2, p. 27-43, 2018.

MARTINS, Fernanda; GAUER, Ruth M. C.. Poder Punitivo e Feminismo: percursos da criminologia feminista no Brasil. Revista Direito e Práxis., Rio de Janeiro , v. 11, n. 1, p. 145-178, Mar. 2020. 
SÁ, Alvino Augusto de. Criminologia clínica e psicologia criminal. São Paulo: Editora Revista dos Tribunais, 2007.

SANTOS, C. M; PASINATO, W. Violência contra as Mulheres e Violência de Gênero: Notas sobre Estudos Feministas no Brasil. Estudios Interdisciplinários de America Latina y El Caribe, v.16, nº 1, p.147-164. Israel: Universidade de Tel Aviv, 2005. 